\title{
Characterization of patients with pre-diabetes in first-level health care service institutions Cali, Colombia
}

\author{
Fabio N. Figueroa ${ }^{1}$, Jessica Morales ${ }^{1}$, Aralí Melgarejo ${ }^{1}$, Jousetp Forero ${ }^{1}$, \\ Gabriel Motoa ${ }^{1}$, Jaime A. León ${ }^{1}$, Andrés C. Londoño ${ }^{1}$, Blanca C. Salazar, MD, MSc ${ }^{2}$
}

SUMMARY

Introduction: Type 2 diabetes (DM 2) is one of the first ten causes of mortality in Colombia. Pre-diabetes is a state of hyperglycemia that associated with other risk factors appears 5-10 years before this disease. It has been reported that controlling the diet and exercise decreases the probability of suffering DM 2 by $60 \%$. This intervention requires establishing the risk in pre-diabetic patients.

Objectives: To detect patients with pre-diabetes who are members of a private health care provider (EPS for its name in Spanish) in Cali and to describe the clinical and epidemiological characteristics related to the risk of developing DM 2.

Materials and methods: This is a cross-sectional descriptive study in patients with altered glucemias (Impaired fasting glucose: $100-125 \mathrm{mg} / \mathrm{dl}$ and impaired glucose tolerance: $140-199 \mathrm{mg} / \mathrm{dl}$ ). Clinical histories were reviewed and surveys on risk factors, habits and perception of knowledge were conducted. We determined: fasting glucose, vital signs, and anthropometric measures.

Results: 111 patients were included (64\% women) whose most common occupation was home duties (39.6\%). The descriptive analysis reported high risk; the results were: noticeable presence of associate pathological antecedents as follows: Diabetes in the family (64\%), obesity (54.1\%), dyslipidemia (72.1\%), and hypertension (66.7\%) in a population with a mean age at 51 years and $10.8 \%$ were under 40 years of age. This great proportion of overweight or obesity ( $86.5 \%)$, according to $\mathrm{BMI}$, influenced the determination of the high cardio-metabolic risk ( $81 \%$, agreeing with the WHO). When evaluating diet with consumption frequency, we still found the intake of simple carbohydrates and animal fats; when reviewing physical activity, $53.2 \%$ of the patients reported activity in the last 7 days according to the International Physical Activity Questionnaire (IPAQ).

Conclusions: $66 \%$ of pre-diabetics did not have diagnosis of some disorder of the metabolism of carbohydrates. More than $70 \%$ of the patients have high risk of DM 2 with pathological antecedents, inadequate health habits, and low perception of disease complications.

Keywords: Pre-diabetic state; impaired glucose tolerance; Diabetes 2; Primary prevention; Metabolic Syndrome X.

Colomb Med. 2011; 42: 98-106

Caracterización de pacientes con prediabetes en instituciones de servicio de salud de primer nivel en Cali, Colombia

\section{RESUMEN}

Introducción: La diabetes tipo 2 (DM 2) es una de las diez primeras causas de mortalidad en Colombia. La prediabetes es un estado de hiperglucemia que, asociado con otros factores de riesgo, se presenta 5-10 años antes de dicha enfermedad. Se ha informado que controlar la dieta y el ejercicio disminuye la probabilidad de padecer DM 2 hasta en $60 \%$. Identificar y caracterizar el riesgo en los pacientes prediabéticos contribuye en la prevención de la DM 2.

Objetivos: Detectar los pacientes con prediabetes afiliados a una EPS privada de Cali, evaluar y describir su estado de riesgo.

1. Students from the Medical Program, Faculty of Health, Universidad del Valle, Cali, Colombia. e-mail: fabio_figueroa@hotmail.com ozono823@hotmail.com aralimelgarejo@hotmail.com forerocorral@hotmail.com gamocar@hotmail.com jaimealeonca@hotmail.com macava191@hotmail.com

2. Associate Professor, Department of Physiological Sciences, Faculty of Health, Universidad del Valle, Cali, Colombia. e-mail: bsblasalaz@gmail.com

Received for publication December 17, 2009 Accepted for publication September 14, 2010 
Materiales y métodos: Se realizó estudio descriptivo transversal en pacientes con glucemias alteradas (glucemia en ayunas, 100-125 mg/dl y glucemia post-carga, 140-199 $\mathrm{mg} / \mathrm{dl})$. Se revisaron historias clínicas y se realizó encuesta de factores de riesgo, hábitos y percepción de conocimientos. Se determinaron glucemia en ayunas, signos vitales y medidas antropométricas.

Resultados: Se incluyeron 111 pacientes (64\% mujeres), con edad promedio de 51 años y $10.8 \%$ menor de 40 años, cuya mayor ocupación fue el hogar (39.6\%). Se encontró alto riesgo para desarrollar DM 2 de acuerdo con los siguientes resultados: alta proporción de antecedentes patológicos asociados como diabetes familiar (64\%), obesidad (54.1\%), dislipidemias (72.1\%) e hipertensión (66.7\%). La gran proporción de sobrepeso u obesidad según IMC hallado (86.5\%), influyó en la determinación del alto riesgo cardiometabólico ( $81 \%$ según criterios de la OMS). Al evaluar dieta con frecuencia de consumo, se encontró todavía ingesta de carbohidratos simples y grasas animales; luego de revisar actividad física, 53.2\% informó actividad en la semana antes del Cuestionario Internacional de Actividad Física (IPAQ).

Conclusiones: Del total de los prediabéticos, 66\% no tenía diagnóstico de algún desorden del metabolismo de los carbohidratos. Más del 70\% de los pacientes tiene alto riesgo de DM 2 con hábitos saludables inadecuados y baja percepción de las complicaciones.

Palabras clave: Estado prediabético; Intolerancia a la glucosa; Diabetes tipo II; Prevención primaria; Síndrome X metabólico.

\section{Colomb Med. 2011; 42: 98-106}

To understand the natural history of DM 2 , allowing to identify patients with prediabetes ${ }^{1}$ who are at risk of developing this disease. Initially, there is resistance to insulin, which produces decreased peripheral consumption of glucose, leading to increased levels of glucose, which during this stage can be between 100$125 \mathrm{mg} / \mathrm{dl}$. This state is known as Impaired Fasting Glucose (IFG). As compensation to resistance, the pancreas increases insulin release and, in a long term a dysfunction of beta cell occurs and decrease the pancreatic secretion. This state is known as Impaired Glucose Tolerance ${ }^{2}$ (IGT) and refers to glucose values between $140-199 \mathrm{mg} / \mathrm{dl}$, two hours after an oral load of $75 \mathrm{~g}$ of glucose in the glucose tolerance test. A patient with pre-diabetes can present these two states or any of them in association with any or some of the following risk factors: obesity/overweight condition, sedentary life style, dyslipidemia, genetic predisposition, hypertension, cigarette smoking, inadequate diet, associated pathologies, age, and ethnicity. These states are part of a prior stage to the development of DM2, which can last between five and ten years. Once the DM 2 is instituted, there is reduction and irreversible damage of the beta cells $\mathrm{s}^{3}$ that diminish insulin secretion in contrast to prediabetic state in which the changes in secretion of the pancreas can be reversed. It is important to remark that to a major state of hyperglycemia increase the risk of micro and macrovascular damage associated with endothelial dysfunction, constituting a risk factor for developing cardiovascular disease ${ }^{4}$.

Diabetes mellitus (DM) is defined according to the World Health Organization (WHO) as a metabolic disease and is classified etiologically into type one and type two ${ }^{5}$. The hyperglycemia of DM is mainly due to resistance and to abnormalities in insulin production ${ }^{6}$. In the long term, it affects micro-and macro-circulation, generating damage in the renal, nervous, and coronary functions.

Currently, DM is an important public health problem because of its high morbidity and mortality, increased health care costs, and decreased quality of life for patients affected for it. The International Diabetes Federation conducts theoretical estimations of the prevalence of DMbased on worldwide epidemiological data. In urban regions for 2010 , a worldwide prevalence of $6.4 \%$ for diabetes and $7.8 \%$ for impaired tolerance to glucose ${ }^{7}$ (pre-diabetes) was estimated, which could rise to $7.7 \%$ and $8.4 \%$, respectively, by 2030 . In Colombia for 2010 , DM prevalence was calculated at $4.8 \%$, which could rise to $6.2 \%$ by 2030 . In the mortality analysis for 2005 in Cali, published by Center for the Development and Evaluation of Politics and Tecnology in Public Health (CEDETES for its name in spanish), DM places 12 th with a death rate of 19.1 per 100 thousand inhabitants ${ }^{8}$.

According to world statistics, DM 2 represents approximately $90 \%$ of the DM cases; its prevalence increases with age and over 65 years of age it is accompanied by great co-morbidity ${ }^{7}$. It is characterized by the partial lack of insulin, slow progression, and genetic association ${ }^{7}$ of $90 \%$ of the cases.

Prevention of DM 2 is a Public Health priority. In this sense, Latin American Diabetes Association ${ }^{9}$ established that, regarding primary prevention infor- 
mation must be disclosed to avoiding the development of this disease in high-risk individuals, encouraging them to modify their risk factors. Multiple studies where there has been early intervention with exercise programs for individuals at high risk of developing DM 2 have revealed greater decrease in the incidence of this disease $(58 \%)$ ) than pharmacological intervention with metformin, given that in this case the decrease only reaches $31 \%{ }^{10}$.

Pre-diabetic patients are in the age range between 20 and 79 years; most are asymptomatic and in some cases are incidentally detected when they have a blood sugar test prior to surgery or during a general check up ${ }^{11}$. Hence, it is important to design public health strategies for early detection of these patients to permit opportune intervention.

This study seeks to determine the socio-demographic characteristics, life style, and risk factors for developing DM 2 and cardiovascular disease in patients with prediabetes. The purpose of this study is to contribute in the development of primary prevention strategies, which permit early identification of individuals with DM 2 risk, so they could be part of intervention and education programs that guide pre-diabetic patients to adopting healthy life styles.

\section{MATERIALS AND METHODS}

An observational, descriptive, cross-sectional study was designed; patients were selected under 65 years of age, because above this age greater prevalence of diabetes than pre-diabetes has been reported in literature, along with high association of other co-morbidities. These patients were affiliated to a private Health Care Service Provider (EPS for its name in Spanish) of the contributive General System of Health Social Security (SGSSS for its name in Spanish) in the city of Cali.

After reviewing the data base at the EPS laboratory regarding altered blood glucose results (fasting glucose between $100-125 \mathrm{mg} / \mathrm{dl}$, and glucose tolerance test between 140-199 mg/dl), taken between 01 January and 31 August of 2008, 6659 results of altered blood glucose were found in total, of which 5857 were results of Fasting glucose and 802 of glucose tolerance tests within the values mentioned. After organizing the results perpatient and determining how many of them presented both tests altered, 406 patients were found whose clinical history was reviewed. We excluded patients previously diagnosed with DM, those with no clinical history, or those who decided not to participate in the study. In the end, there were 139 patients who were called and accepted to be part of the investigation; when subjected to the fasting glucose test, 28 patients presented alteration for this test and were excluded because they completed the criteria for the diagnosis for DM 2, leaving 111 pre-diabetic patients. With this number of patients, we obtained primary and secondary information on the DM 2 risk factors, through a guided survey and review of the clinical history, respectively.

From the clinical history we recorded on a written format information regarding the pathological antecedents (diseases associated to hyperglycemia and hyperinsulinemia), the pharmacological antecedents (medications consumed during the last year), and the results of the laboratory tests (glycemia and lipid profile). Through the guided survey, we gathered information about socio-demographic characteristics (gender, age, socio-economic level, ethnicity, and marital status), updated personal and family pathological antecedents (diseases associated to hyperglycemia and hyperinsulinemia), and asked about habits (cigarette and alcohol consumption) and about healthy life styles. The information about physical activity and diet was recorded by using the International Physical Activity Questionnaire (IPAQ), validated in Argentina ${ }^{12}$ and the questionnaire of the frequency of food intake during 24 hours, respectively. With the information obtained through the IPAQ each subject was classified as very active, active, insufficiently active, or sedentary, considering the intensity, duration, and frequency of the physical activity during the last week, and the following classification scheme ${ }^{12}$ (Table 1).

The guided survey also inquired about the perception about DM 2 and pre-diabetes; questions were made regarding the pre-diabetes diagnosis, the risk factors, diseases associated with DM 2, the complications of DM 2, glycemia control and healthy life styles. After collecting this information from the 111 patients, we proceeded to taking anthropometric measurements. These were determined in the following manner: weight (kg) with Health Scale Meter ${ }^{\circledR}$ with one decimal value ${ }^{14}$. Height was determined with a altimeter 1. With height and weight measurements the Body Mass Index (BMI) was calculated. Waist circumference was measured 
Table 1

IPAQ classification of the level of activity

Sedentary. Did not engage in physical activity for at least 10 continuous minutes during the week.

Insufficiently active. Engages in physical activity for at least 10 minutes per week, but insufficient to be classified as active. May be divided into two groups:

A. Reaches at least one of the recommended criteria

a. Frequency: 5 days/week or

b. Duration: $150 \mathrm{~min} /$ week

B. Did not reach any of the recommendation criteria

Observation: To conduct this classification, add the frequency and the duration of the different types of activity (Walking + Moderate + Vigorous)

Active. Complied with the recommendations:

a. Vigorous: $\geq 3$ days/week and $\geq 20$ min per session

b. Moderate or walking: $\geq 5$ days/week and $\geq 30$ min per session

c. Any activity added: $\geq 5$ days/week and $\geq 150 \mathrm{~min} / \mathrm{week}$ (Walking + Moderate + Vigorous)

Very active. Complied with the recommendations and:

a. Vigorous: $\geq 5$ days/week and $\geq 30 \mathrm{~min}$ per session or

b. Vigorous: $\geq 3$ days/week and $\geq 20$ min per session + moderate and/or walking : $\geq 5$ days/week

and $\geq 30$ min per session

International Physical Activity Surveillance (IPAS, TANGO); Buenos Aires, Argentina, 2003

with a Lufkin measuring tape $0.5 \mathrm{~cm}$ wide, two to three meters long and $0.1 \mathrm{~cm}$ of resolution, using the technique of the tape juxtaposed on the abdominal zone at an intermediate height between the last rib and the iliac crest. Normal values were considered ${ }^{13}$ for women $<80$ $\mathrm{cm}$ and for men $<90 \mathrm{~cm}$. Blood pressure was taken with the ausculatory method and using a Littman Master Classic Stethoscope and a Wellch Allyn Tensiometer. A reference value ${ }^{14}$ for Blood Pressure $<130 / 85$ was considered.

After $12 \mathrm{~h}$ of fasting, a blood simple was taken via venipuncture on the antecubital vein; the blood was collected in vaccutainer tubes without anticoagulant and immediately stored at $4{ }^{\circ} \mathrm{C}$ and separated from the serum through centrifuge at $3000 \mathrm{rpm} / 15 \mathrm{~min}$; thereafter, it was stored at $-20^{\circ} \mathrm{C}$, to then measure glucose in $\mathrm{mg} /$ $\mathrm{dl}$ and, thus, update the value of fasting glucose and evaluate the patients that would be excluded because they fulfilled the criteria for the DM 2 diagnosis.

The results were analyzed in Epi-Info CDC 3.5.1 (2008). Proportions were used to analyze qualitative variables and central tendency measurements for quantitative variables, assuming a $5 \%$ of error $(p<0.05)$.
The $\mathrm{Z}$ test was used to evaluate the difference between proportions.

This study was approved by the Ethics Committee at Universidad del Valle and the Research Committee at the EPS. The informed consent form was read and explained to each patient; once understood and accepted, 111 patients signed it prior to starting the survey. The results were given to the patients within the framework of an educational conference on pre-diabetes and prevention of DM 2. Results compatible with DM 2 diagnosis were reported to the EPS.

\section{RESULTS}

The risk factors evaluated in these patients are presented in the following categories, which were previously described:

Regarding the socio-demographic characteristics, we found that most of the cases studied were women (64\%), the mean age was 51 years \pm 10.9 , with $89.2 \%$ between $40-65$ years of age and $10.8 \%$ below 40 years of age. A total of $86.5 \%$ were classified as mestizo (Table 2 summarizes other characteristics). 
Table 2

Socio-demographic characteristics by gender, socioeconomic level, occupation, and marital status

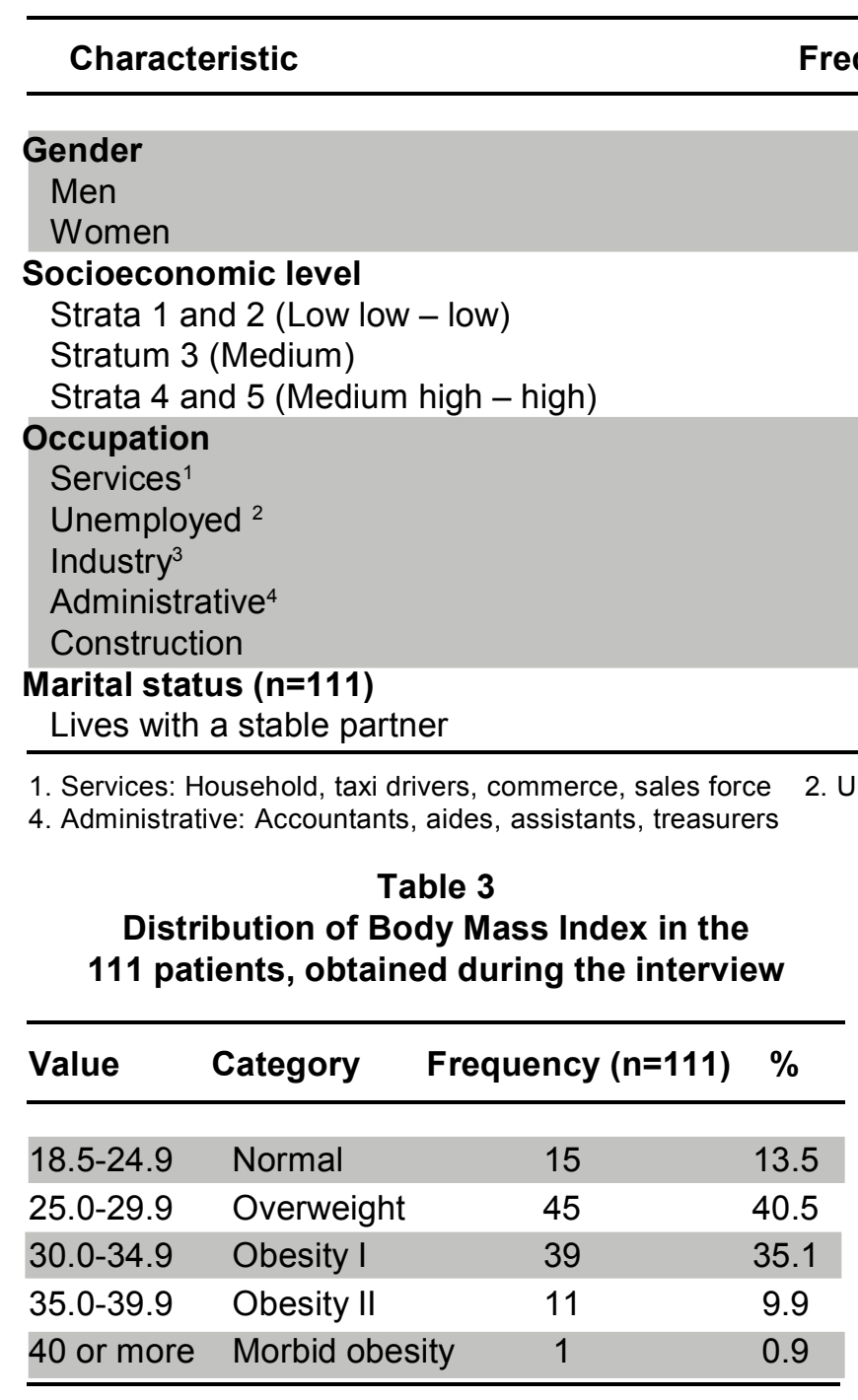

Findings on patient pathological antecedents were: dyslipidemia $80(72.1 \%)$, hypertension $74(66.7 \%)$, obesity $60(54.1 \%)$, altered blood glucose $49(44.1 \%)$, and cardiovascular disease 29 (26.1\%). We noted significant increase when using the Chi square test $(p \leq 0.05)$ in the frequency analysis for dyslipidemia, hypertension, and cardiovascular disease in patients between 50 and 60 years of age. No significant differences were found for gender. The frequency distribution of some of the pathologies explored like family antecedents was similar to that of personal antecedents; these were: hypertension $(65.8 \%)$, undifferentiated diabetes $(64 \%)$, cardiovascular disease $(47.8 \%)$, and obesity $(41.4 \%)$.

36.0
40
71

$49 \quad 44.1$

$55 \quad 49.5$

$\begin{array}{ll}7 & 6.3\end{array}$

75
15 67.6

$15 \quad 13.5$

$10 \quad 9.0$

98.1

2

$86 \quad 77.5$

Unemployed: Retired or students 3. Industry: Carpenters, welders

Regarding pharmacological antecedents and according to that reported in literature, we found an important consumption of medications associated ${ }^{13}$ to increased intolerance to glucose; these are: hydrochlorothiazide (43.2\%) and beta blockers (16.2\%). However, we also found consumption of medications reported as protectors ${ }^{10}$ like metformin in $9 \%$ of the patients.

From the evaluation of anthropometric measurements, $13.5 \%$ presented BMI within normal limits; the remaining population was overweight or showed some degree of obesity (Table 3), without notable differences for gender. It was also found that $86.5 \%$ had central obesity (waist circumference $\geq 90 \mathrm{~cm}$ in men and $\geq 80$ $\mathrm{cm}$ in women).

Regarding the classification systems that permitted evaluating the risk for these patients, we considered the presence of metabolic syndrome according to criteria from the International Diabetes Federation in $2006^{13}$, based on those by the Adult Treatment Panel III (ATPIII), of which only three could be selected, which were the ones determined:

1. Prescription of antihypertensive medications in $55.9 \%$

2. Elevated fasting glucose $(\geq 100 \mathrm{mg} / \mathrm{dl})$ in $73.9 \%$

3. Waist circumference $\geq 90 \mathrm{~cm}$ in men and $\geq 80 \mathrm{~cm}$ in women: in $82.5 \%$ and $88.7 \%$, respectively

Upon applying these criteria, we found $38.7 \%$ of 
Table 4

Risk of cardiovascular disease, DM 2 and hypertension in the 111 patients, according to BMI and waist circumference obtained during the interview*

\begin{tabular}{|c|c|c|c|}
\hline \multirow[t]{2}{*}{$\operatorname{BIM}\left(g / m^{2}\right)$} & \multirow[t]{2}{*}{ Category } & \multicolumn{2}{|c|}{ Waist circumference } \\
\hline & & $\begin{array}{c}<90 \mathrm{~cm} \text { men } \\
<80 \mathrm{~cm} \text { women }(\%)\end{array}$ & $\begin{array}{c}\geq 90 \mathrm{~cm} \text { men } \\
\geq 80 \mathrm{~cm} \text { women }(\%)\end{array}$ \\
\hline $18.5-24.9$ & Normal (13.5) & - & - \\
\hline $25.0-29.9$ & Overweight (40.5) & Increased (5.4) & High (35.1) \\
\hline $30.0-34.9$ & Obesity I (35.1) & High & Very high (35.1) \\
\hline $35.0-39.9$ & Obesity II (9.9) & Very high & Very high (9.9) \\
\hline 40 or more & Obesity III (0.9) & Extremely high & Extremely high (0.9) \\
\hline
\end{tabular}

* Adapted from the National Institutes of Health (NIH). National Heart, Lung, and Blood Institute (NHLBI). Clinical guidelines on the identification, evaluation, and treatment of overweight and obesity in adults. US Department of Health and Human Services, Public Health Service; 1998.

metabolic syndrome, still needing the proportion of this syndrome corresponding to criteria that could not be determined. There were no significant differences according to gender.

With the other system that permits evaluating the risk of cardiovascular disease, DM 2 and hypertension in the 111 patients, we used the joint analysis of results of BMI and waist circumference, finding that $35 \%$ of the patients were overweight with central obesity, $45 \%$ with grade I or II obesity and with central obesity, and $1 \%$ had morbid obesity and central obesity. The determination and categorization of this risk can be seen in Table 4.

Regarding habits, it was found that $66.7 \%$ stated not currently smoking, $26.1 \%$ said they were ex smokers, and $22.5 \%$ said they were active consumers of alcohol.

With respect to feeding habits reported by the cases, we found a daily consumption of simple carbohydrates at $25 \%$. Regarding whole food integral nutrition, $12 \%$ has a daily consumption which is part of a $37 \%$ total consumption. A total of $19 \%$ reported consuming foods derived from animal fat, as opposed to $43 \%$ who reported intake of foods derived from vegetable fat. Some $66 \%$ stated they never consumed whole foods and $85 \%$ denied consuming low-sugar and low-fat milk.

Regarding physical activity, we found that $53.2 \%$ of the patients were actives and $46.8 \%$ sedentary or insufficiently actives in according to the IPAQ classification (Table 1).

After evaluating risk perception regarding their pre- diabetic condition and DM 2, it was found that $71.2 \%$ stated that diabetes and pre-diabetes were different. Results on other perceptions were: more than $90 \%$ of the patients recognized the harmful effect of consuming simple carbohydrates, of hyperglycemia, and of being overweight or obese. Other risk factors acknowledged were: family antecedents $(84.7 \%)$, sedentary life style $(80.2 \%)$, and dyslipidemia (64.9\%). The following were recognized as DM 2 complications, eye problems (34.2\%), poor scarring (26.1\%), cardiovascular disease, kidney damage, and comatose state (22.5\%). The sources of information recognized by the patients were: health care personnel (50\%), communication media (23.4\%), and third parties (17.1\%). When inquiring on the frequency in conducting glucose control tests, the patients considered it adequate: once a month $(20 \%)$, every three months $(10.9 \%)$, every six months $(38.2 \%)$ and each year $(25.5 \%)$.

\section{DISCUSSION}

The results obtained in the study for some risk factors coincide with those found in other research conducted with similar populations ${ }^{14}$, which could mean that said factors are more reliable in predicting the risk of developing DM 2. The mean age of the population studied ranged between 50 and 60 years, as described in several conducted in the United States ${ }^{15}$. In the same way, significant increase was found in the onset of dyslipidemia, hypertension, and cardiovascular disease, 
conditions that have been physio-pathologically associated ${ }^{16}$ with insulin resistance in these patients.

According to the history of the disease, insulin resistance had to be occurring since earlier, given that the cut or the study was made when there was alteration in fasting glucose and glucose tolerance tests. An aggravating condition in this sense is the identification of several patients with pre-diabetes between 20 and 30 years of age, agreeing with the tendency currently reported throughout the world, according to which both the prevalence to pre-diabetes and DM 2 are increasing at earlier ages ${ }^{17}$. Because of this, the American Diabetes Association(ADA) recommends screening patients below 45 years of age with risk factors associated to developing DM $2^{18}$. This is established in Colombia through the DM 2 care guide from the Ministry of Social Protection ${ }^{11}$. However, in spite of the evidence ${ }^{10}$ of the need to intervene with healthy life styles, in addition to screening and recommendations to patients with pre-diabetes, few countries have established intervention as part of public health programs for these patients. In Colombia, it is necessary to develop projects favoring the implementation of these programs.

Similar to that found in other studies ${ }^{15}$, we found a man-woman ratio of $1: 1.8$. We do not know if this could have anything to do with the fact that household chores correspond to the most frequent occupation. To elucidate these findings it would be necessary to implement a study with greater coverage.

The risk factors identified in this study were: family antecedents, dyslipidemia, hypertension, obesity, cardiovascular alterations, sedentary life style, and inadequate diet, which correspond to that reported in literature for pre-diabetic patients with risk of developing DM $2{ }^{19}$. In this regard, it is important to indicate that impaired glucose tolerance is considered an independent risk factor for the development of cardiovascular disease ${ }^{20}$.

It has been reported in literature that a BMI above 25 $\mathrm{kg} / \mathrm{m}^{2}$ is a prediction factor for DM $2^{19}$. This study found that $86.5 \%$ of the patients surpassed this BMI value and, hence, were overweight or obese. Most of these patients, also had central obesity and a high risk of metabolic and cardiovascular disease, similar to that reported in literature ${ }^{20}$. Nevertheless, it was found that only $38 \%$ of the patients had metabolic syndrome, according to IDF criteria. It is likely that this study only reflects a part of all the patients with the syndrome because only three of its five definition criteria were determined. When the BMI value and the waist circumference were used as indicators of metabolic and cardiovascular risk, as proposed by the WHO, it was found that $81 \%$ of the patients had from high to very high risk. This can reflect, in turn, the real situation, given that all the criteria were considered in all the patients.

The association between obesity and the development of cardiovascular and/or metabolic disease has been explained in literature through the mechanisms implied in the genesis of these pathologies. It is suggested that in obesity there is micro-vascular impairement that leads to endothelial dysfunction, which increases peripheral vascular resistance, and consequently blood pressure, as well as diminishing the peripheral consumption of glucose leading to insulin resistance and hypertension. With regard to the above has been proposed, that the blockage of mechanisms implied in micro-vascular alterations could impede the development of associated chronic disease, among them DM $2^{16}$.

The information about the diet only refers to the frequency of food intake, without considering the number of portions consumed or the time transpired since its instauration. The daily or weekly consumption referred to by the patients of the nutritional groups affecting body weight (carbohydrates and fats) was low, and although that of simple carbohydrates should be null; these finding did not correspond to the BMI evaluation. Also, the intake of protector nutrition ${ }^{21}$ like whole foods or low-fat milk was still very restricted, which could be due to their high costs and to the fact that said diet is not part of the gastronomic customs in our region. With the results obtained, we could surmise that there is no real perception of the diet and that greater clarity is needed on the importance of the protector foods.

Regarding physical activity, we found similar proportions of activity and inactivity. What has been found in literature is that weight changes are observed after six months and glycemia changes are observed after one year of continuous diet and physical activity intervention, where 700 kilocalories are consumed after $2.5 \mathrm{~h}$ per week of physical activity ${ }^{10}$. The information obtained was very subjective, given that it 
was from the perception of the patient in terms of the time and intensity of the physical activity during the seven days prior to the day of the survey. The information was empirical because the description of the activities did not report if they were attending intervention programs and much less in their pre-diabetic condition, mainly because in our health care entities this type of preventive intervention still does not exist as it does in other countries ${ }^{22}$.

Upon inquiring about awareness of the frequency at which glycemia control tests should be conducted, it was found that most of the population knew that such control should be carried out every six and/or 12 months, which corresponded with the frequencies they reported for taking the test.

The patients included in this study had both altered tests (fasting glucose and glucose tolerance test), i.e., they were at a moment of the history of the disease that was very close to DM 2. However, although they recognized the risk of developing DM 2, 64\% of the patients had no clear idea of being close to developing it.

\section{CONCLUSIONS}

According to criteria from the WHO, $81 \%$ of the patients had high cardio-metabolic risk. In over half the cases, pathological antecedents were found clearly related with the state of insulin resistance like dyslipidemia, hypertension, and obesity, which were also present as family antecedents. An aggravating factor for this situation is that the medical recommendations received from the health care service are not sufficient, given that the conduct they have regarding physical activity and nutrition was not adequate to control excess weight and altered fasting glycemia. On the other hand, according to the perception reported by patients regarding DM 2, most patients recognize the risk factors for developing it, but few perceive the complications that such disease can bring for their health.

A high percentage of the pre-diabetic individuals had not been diagnosed for disorder of carbohydrate metabolism, for which a model is required for early identification and detection, like that developed in this study, which permits an appropriate promotion and prevention of these patients.
Finally, new studies are necessary in a Latin American population with bigger samples, including individuals belonging to public and private health care systems, in whom we can also study other variables of cardio-metabolic risk like lipid profile, glycated hemoglobin, and c-reactive protein, which permit recognizing differences with other widely studied populations and design more specific strategies, which are cost effective and viable in Latin America to prevent the development of DM 2 with adequate intervention in healthy life style habits.

Conflict of interests. There were no conflicts of interests with the Institution or with the Research Group supporting the development of this project.

\section{ACKNOWLEDGMENTS}

The execution of the project was possible due to the institutional support by COMFANDI (Caja de Compensación Familiar ANDI) and by its research committee. Likewise, we remark the support from the Group on Nutrition at the Faculty of Health of Universidad del Valle and the intervention by Professor Elsa Patricia Muñoz from the same university.

\section{REFERENCES}

1. Codario R. Pathophysiology of type 2 diabetes. In: Type 2 diabetes, pre-diabetes, and the metabolic syndrome: The primary guide to diagnosis and management. Totowa: Humana Press Inc; 2005. p. 1-12.

2. Rao S, Disraeli P, McGregor T. Impaired glucose tolerance and impaired fasting glucose. Am Fam Physician. 2004; 69: 1961-8.

3. Leahy J. $\alpha$-Cell dysfunction in type 2 diabetes mellitus. In: Kahn C. R, Weir G, King G, Jacobson A, Smith R, Moses A (eds). Joslin's diabetes mellitus.14th ed. Boston: Lippincott Williams \& Wilkins; 2006. p. 449-61.

4. Ceriello A. Post-Prandial endothelial dysfunction, oxidative stress, and inflammation in type 2 diabetes. In: Packer L, Sies $\mathrm{H}$, (eds). Oxidative stress and inflammatory mechanisms in obesity, diabetes, and the metabolic syndrome. Boca Raton: CRC Press; 2008. p. 123-37.

5. World Health Organization. Definition, diagnosis and classification of diabetes mellitus and its complications: Report of a WHO Consultation. Geneva: WHO/NCD/NCS/ 99.2; 1999.

6. Nathan D, Delahanty L. Beating diabetes. Chicago: McGrawHill; 2005. p.1-19.

7. Sicree R, Shaw J, Zimmet P. The Global Burden: Diabetes and impaired glucose tolerance. In: Diabetes Atlas. 4th ed. 
Brusselas: International Diabetes Federation (IDF); 2009

8. Centro para el Desarrollo y Evaluación de Políticas y Tecnología en Salud Pública (CEDETES), Universidad del Valle, Secretaria de Salud Pública Municipal de Cali. Situación de salud de Cali. Una mirada desde la salud pública. Cali: CEDETES, UniValle, SSPMC; 2007.

9. Asociación Latinoamericana de Diabetes. Guías ALAD de diagnóstico, control y tratamiento de la diabetes mellitus tipo 2. Bogotá, DC: Asociación Latinoamericana de Diabetes; 2007.

10. Diabetes prevention program research group. Reduction in the incidence of type 2 diabetes with lifestyle intervention or metformin. N Engl J Med. 2002; 346: 393-403.

11. Ministerio de la Protección Social. Guía de atención de la diabetes mellitus Tipo 2. Bogotá, DC: Ministerio de la Protección Social; 2007.

12. Bazán N, Díaz G, Kunik H, O'Connor C, Gavini K. IPAS TANGO: La aplicación del Cuestionario Internacional de Actividad Física (IPAQ) en la Ciudad de Buenos Aires. Buenos Aires: Instituto Superior de Deportes, Asociación Metropolitana de Medicina del Deporte; 2003.

13. International Diabetes Federation. The IDF consensus worldwide definition of the metabolic Syndrome. Brussels: Promoting Diabetes Care, Prevention and a Cure Worldwide; 2006.

14. Blaha M, Bansal S, RoufR, Golden S, Blumenthal R, Defilippis A. Practical «ABCDE» approach to the metabolic syndrome. Mayo Clin Proc. 2008; 83: 932-43.
15. Benjamin S, Valdez R, Geiss L, Rolka D, Venkat K. Estimated number of adults with pre-diabetes in the US in 2000. Diabetes Care. 2003; 26: 645-9.

16. Jonk A, Houben A, De Jongh R, Serné E, Schaper N, Stehouwer C. Micro-vascular dysfunction in obesity: A potential mechanism in the pathogenesis of obesity associated insulin resistance and hypertension. Physiol Rev. 2007; 22: 252-60.

17. Dabelea D, Bell R, D’Agostino R, Imperatore G, Johansen J, Linder B, et al. Incidence of diabetes in youth in the United States. JAMA. 2007; 297: 2716-24.

18. American Diabetes Association. Standards of medical care in diabetes, 2010. Diabetes Care. 2010; 33 (Suppl 1): S11-61.

19. Alberti KG, Zimmet $P$, Shaw J. International Diabetes Federation: a consensus on type 2 diabetes prevention. Diabet Med. 2007; 24: 451-63.

20. Bovet P, Faeh D, Paccaud F, William J, Yerly P. Diabetes and pre-diabetes are associated with cardiovascular risk factors and carotid/femoral intima-media thickness independently of markers of insulin resistance and adiposity. Cardiovas diabetol. 2007; 6: 32.

21. Serra M, Aranceta LI, Mataix J. Nutrición y salud pública. $2^{\mathrm{a}}$ ed. Barcelona: MASSON; 2006.

22. Seidel M, Powell R, Piatt G. Translating the diabetes prevention program in an urban underserved community: long term sustainability of positive clinical outcomes. Diabetes. 2007; 56 (Supp): A42. 